\title{
LARGE-SCALE-FLOW INTERACTIONS WITH THE ALPS AND THEIR IMPACT ON THE LOW-LEVEL TEMPERATURE FIELD IN THE NORTHERN FORELAND
}

\author{
Günther Zängl \\ Meteorologisches Institut der Universität München, Theresienstraße 37, D-80333 München, Germany \\ E-mail: guenther@meteo.physik.uni-muenchen.de
}

\begin{abstract}
Numerical simulations are presented to examine the sensitivity of the temperature field in the northern Alpine foreland on the large-scale wind direction. The simulations are set up such that changing the wind direction does not create any large-scale systematic temperature advection, thereby isolating the effects of the flow interaction with the Alps. The results show indeed an appreciable impact. In the afternoon, temperatures tend to be higher for southerly flow directions than for northerly ones, as might be expected from the fact that subsidence in the lee of the Alps causes warming while upslope flow is related to cooling. In the morning, however, the lowest temperatures are found for easterly directions while northwesterly flow shows the highest temperatures, followed by westerly flow. The primary reasons for this behaviour are the asymmetry of the flow around the Alpine massif as a whole and the interaction of the friction-induced ageostrophic wind component with the Alps.
\end{abstract}

Keywords - Numerical modelling, mountain effects, boundary layer

\section{INTRODUCTION}

It is well known from daily experience that temperatures in central Europe tend to be higher under southerly flow conditions than for northerly large-scale flow. Of course, this primarily reflects the advection of different air masses. Likewise, air masses advected from the east tend to be drier than those coming from the west due to the land-sea contrast, implying that the average diurnal temperature range tends to be larger for easterly flow than for westerly flow. In winter, easterly flow is also related to much lower temperatures than westerly flow, which again reflects the land-sea contrast. However, it is an open question to what extent these airmass-related differences are modified by the flow interaction with the Alpine massif. Intuitively, one might expect that subsidence in the lee of the Alps causes warming while large-scale lifting on the windward side induces cooling, implying that in the northern Alpine foreland, the advective effects are reinforced by orographic effects. However, it is difficult to separate the contributions from large-scale advection and mesoscale flow modification on the basis of observational data. Therefore, this study presents semi-idealized numerical simulations which are designed such that the ambient wind direction can be varied without inducing large-scale temperature advection. This allows for isolating the effects of Alpine flow modification.

\section{MODEL AND SETUP}

The simulations presented in this paper have been performed with the nonhydrostatic mesoscale model MM5, which has been developed at Pennsylvania State University and the National Center for Atmospheric Research (see Grell et al. 1995 for a model description). They are semi-idealized in the sense that they combine realistic topography with idealized large-scale flow conditions. The simulations are computed on three interactively nested domains having a horizontal resolution of $27 \mathrm{~km}, 9 \mathrm{~km}$ and $3 \mathrm{~km}$, respectively. The outer domain covers a large part of Europe and mainly serves the purpose to move the lateral model boundaries sufficiently far away from the domain of interest. The innermost domain covers the eastern Alps and the adjacent northern foreland (see Fig. 3). In the vertical, 41 unevenly spaced levels are used. The lowermost half-sigma level is at about $10 \mathrm{~m}$ AGL (above ground level), and the vertical resolution ranges from $30 \mathrm{~m}$ near the surface to about $750 \mathrm{~m}$ near the upper boundary $(100 \mathrm{hPa})$. Further details on the model configuration are provided in Zängl (2005). 

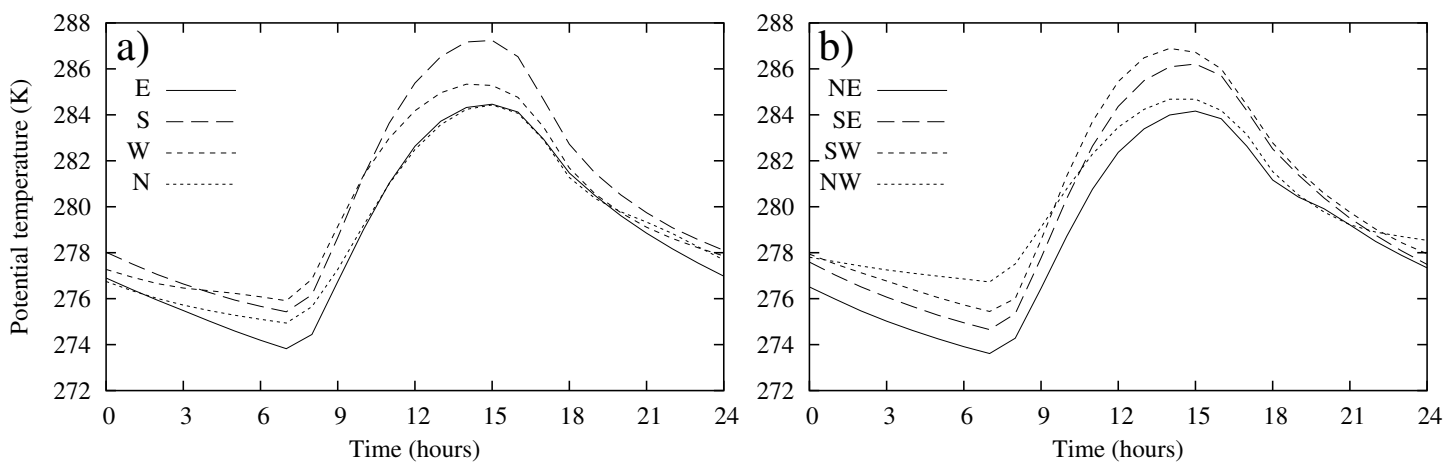

Figure 1: Potential temperature at the lowermost model level, averaged over the area indicated in Fig. 3a. Results are shown for the second day of the simulations.

The large-scale wind field used to drive the simulations is constant in time, horizontally homogeneous, and in geostrophic balance with the pressure field except for the boundary layer where the effects of surface friction are taken into account. For consistency, a spatially constant Coriolis force of $10^{-4} \mathrm{~s}^{-1}$ is used. The wind speed corresponding to geostrophic balance is set to $10 \mathrm{~m} \mathrm{~s}^{-1}$ at sea level and increases linearly with height up to $25 \mathrm{~m} \mathrm{~s}^{-1}$ at tropopause level $(250 \mathrm{hPa})$, above which it remains constant. The wind direction is constant with height and is varied from $0^{\circ}$ (northerly flow) through $315^{\circ}$ (northwesterly flow) at increments of $45^{\circ}$. The temperature profile in the model centre $\left(48^{\circ} \mathrm{N}, 12^{\circ} \mathrm{E}\right)$ starts with $5^{\circ} \mathrm{C}(278.15 \mathrm{~K})$ at sea level and assumes a tropospheric (stratospheric) vertical gradient of $-6.5 \mathrm{~K} \mathrm{~km}^{-1}\left(0 \mathrm{~K} \mathrm{~km}^{-1}\right)$. To account for the thermal wind relation, the temperature field involves horizontal gradients, but it is pointed out that there is no advection of large-scale temperature gradients due the absence of directional shear. The tropospheric (stratospheric) relative humidity is set to $35 \%$ (10\%), which proved to be low enough to prevent the formation of clouds except over a few high Alpine peaks. The simulations make use of a full suite of parameterizations in order to allow for a proper representation of the relevant physical processes (see Zängl 2005 for details). To exclude advective effects due to landuse inhomogeneities, surface parameters representative for grassland are applied everywhere (even where there is water in reality). Moreover, radiation is computed for a fixed date (October 15) and for fixed geographical coordinates $\left(48^{\circ} \mathrm{N}\right.$ and $\left.0^{\circ} \mathrm{E}\right)$. The simulations are started at $00 \mathrm{UTC}$ and are integrated over 48 hours, the first 24 of which serve for spin-up purposes. All results presented in the next section refer to the second simulation day.

\section{RESULTS}

A summary of the diurnal surface temperature evolution in the Alpine foreland is displayed in Fig. 1 for all eight simulations conducted in this study. Data are shown for the lowermost half-level (approx. $10 \mathrm{~m}$ AGL) and are averaged over the area indicated in Fig. 3a. The overall shape of the diurnal temperature cycle is similar for all wind directions, which is not surprising since the large-scale parameters have been chosen such as to avoid the formation of notable cloud cover. Nevertheless, the spread between the coldest and the warmest run is more than $3 \mathrm{~K}$ for both the temperature minimum at sunrise and the temperature maximum in the afternoon. Thus, the impact of the flow interactions with the Alps is by no means negligible. Throughout the day, the coldest temperatures are obtained for the NE run, but the ordering of the other runs changes during the day. In the afternoon, the cold-to-warm ranking list is NE, (N, E), NW, W, SE, SW and S, where the brackets mean that the average temperature maxima are virtually equal for $\mathrm{N}$ and $\mathrm{E}$. In the morning, however, the order is NE, E, SE, N, (S, SW), W and NW.

Thus, the model results are in agreement with simple dynamical considerations (upslope flow induces cooling, downslope flow causes warming) in the afternoon only. Most notably, the highest morning temperatures are found for northwesterly flow, which is intuitively associated with rather cold weather. On the other hand, an easterly flow component generally favours low morning temperatures. Moreover, the surface temperatures for easterly flow are consistently colder than for westerly flow although the flow is parallel to the Alps in both cases. In the morning, westerly flow even exhibits the second-highest temperatures, being still warmer than southwesterly or southerly flow.

To shed some light on the dynamical reasons for this behaviour, Fig. 2 shows average vertical profiles of 

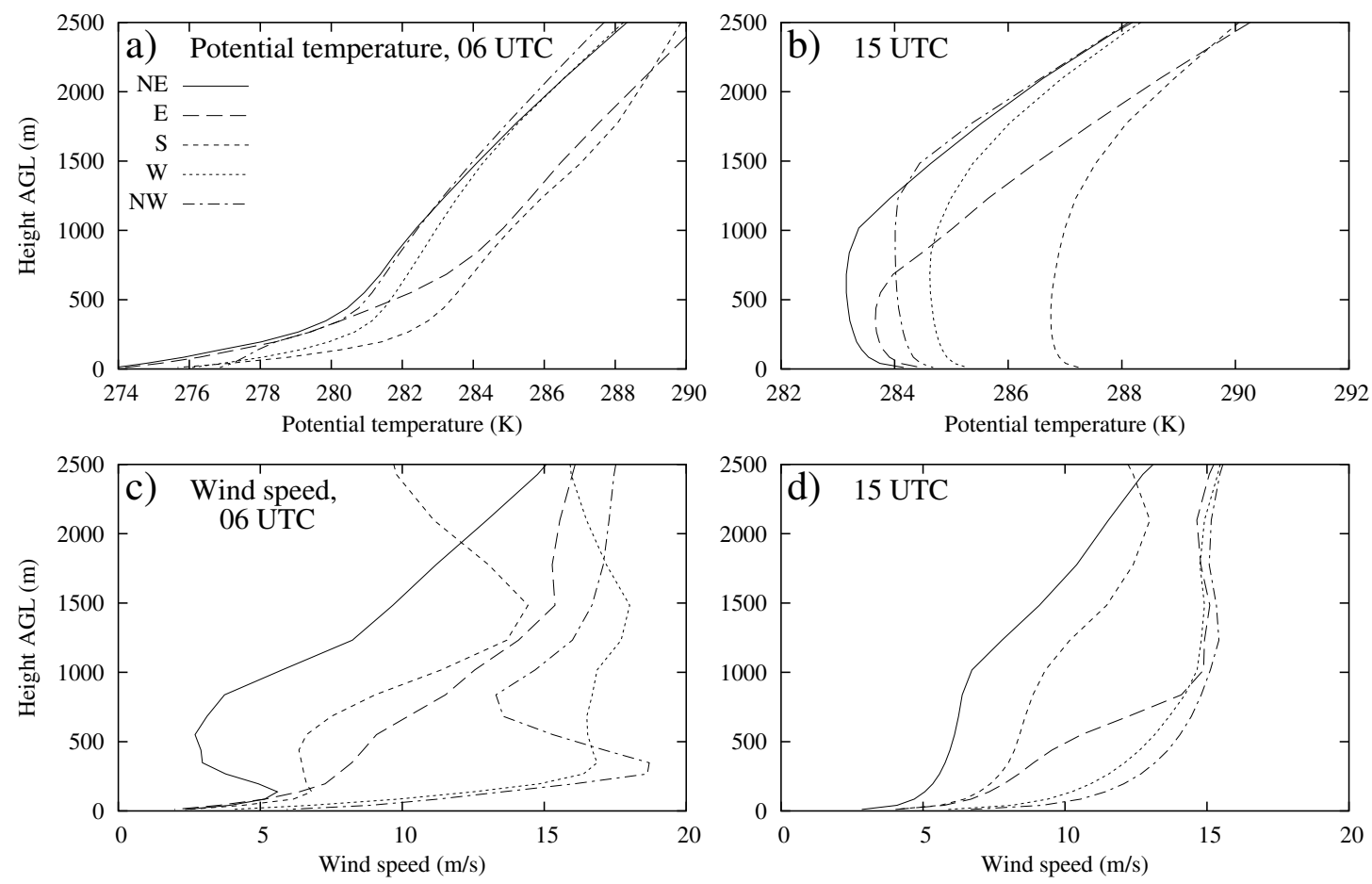

Figure 2: Spatially averaged vertical profiles of potential temperature $(a, b)$ and wind speed $(c, d)$ at 06 UTC and 15 UTC of the second day of the simulations. Line keys are indicated in (a).

potential temperature and wind speed for the simulations NE, E, S, W and NW. For westerly and easterly flow, low-level wind fields (approx. $100 \mathrm{~m}$ AGL) and vertical cross-sections of the wind and potential temperature field are added in Figs. 3 and 4.

Comparing the flow fields displayed in Fig. 3 reveals that the low-level wind speed is substantially higher for westerly wind than for easterly wind, which might appear surprising since the ambient flow is roughly parallel to the Alpine crest in both cases. The primary reason for this discrepancy is related to the Coriolis force, which induces an asymmetric flow around the Alpine massif as a whole. For westerly large-scale flow, for example, the majority of the impinging airmass is deflected towards the north, leading to enhanced winds in the northern Alpine foreland. For easterly flow, the opposite is the case. Note also that this flow asymmetry is reinforced by the arc-like shape of the Alps. As a consequence, westerly large-scale flow tends to be associated with stronger turbulent vertical mixing than easterly flow, which in turn leads to higher morning temperatures.

Another important difference between westerly and easterly flow conditions is related to the frictioninduced ageostrophic wind component in the boundary layer. This ageostrophic wind component is northerly (southerly) for easterly (westerly) ambient flow, which has the consequence that the radiatively cooled surface layer is piled up along the Alpine foothills for easterly flow but advected away from the Alps for westerly flow (Fig. 4). Therefore, the nocturnal surface inversion tends to be significantly thicker for easterly flow than for westerly flow, which in turn reinforces the above-mentioned differences in the efficiency of turbulent vertical mixing. Moreover, the southerly low-level wind component present for westerly ambient flow entails advection of potentially warmer air descending from the Alps (Fig. 4a), implying that there is also a direct advective contribution to the temperature differences between the $\mathrm{W}$ and $\mathrm{E}$ cases.

For NW flow, the nocturnal surface temperatures are even higher than for westerly flow because the flow deflection by the Alps leads to the formation of a pronounced low-level jet in this case (Fig. 2c). During the day, however, the cooling effect due to the lifting of the flow on the windward side of the Alps dominates. On the other hand, NE flow is associated with cold low-level temperatures throughout the day, and also exhibits the lowest wind speeds below $2 \mathrm{~km}$ AGL. This can be traced back to the fact that for this wind direction, a flow-splitting point separating westerly from easterly low-level flow parallel to the Alps tends to lie within the domain of interest (not shown). Due to the weakness of the low-level winds, nocturnal turbulent vertical mixing is comparatively small in the NE case, which allows for building up a pronounced surface inversion. Another important contribution to the low temperature level in the NE case arises from the adiabatic cooling 

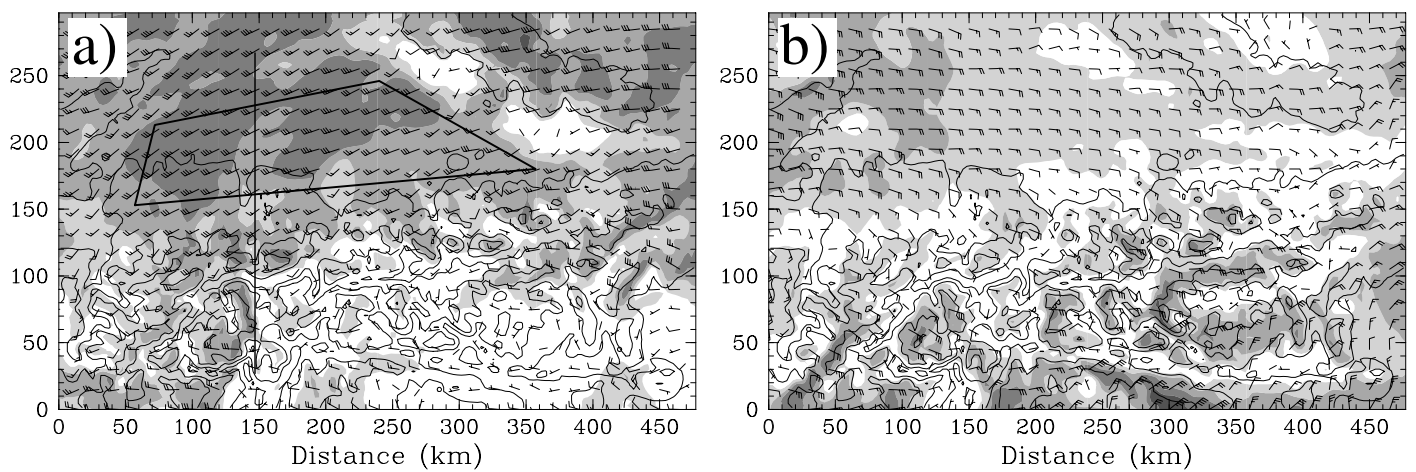

Figure 3: Wind fields at $90 \mathrm{~m}$ AGL at $06 \mathrm{UTC}$ for simulations (a) W, (b) E. A full barb corresponds to a speed of $5 \mathrm{~m} \mathrm{~s}^{-1}$, and shading denotes absolute wind speed with an increment of $5 \mathrm{~m} \mathrm{~s}^{-1}$.
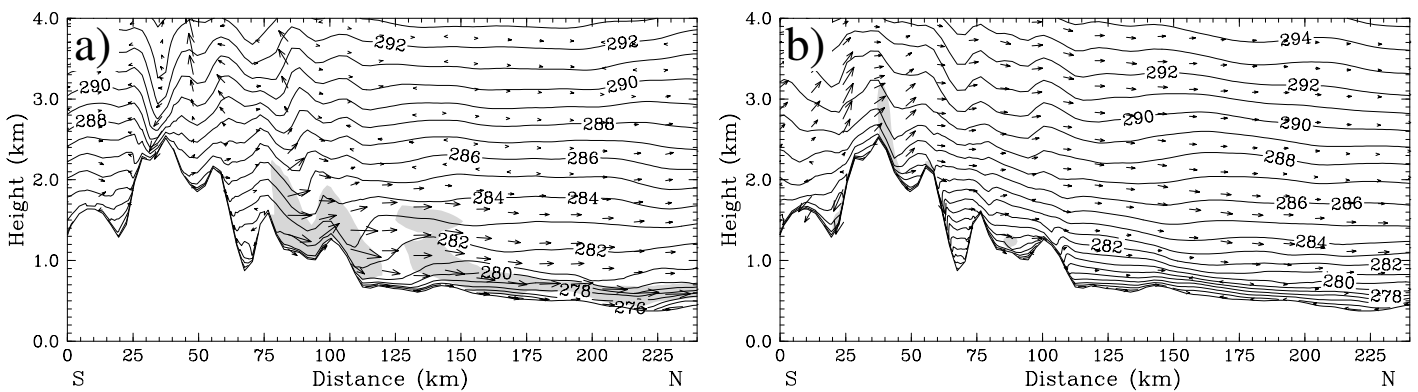

Figure 4: Vertical cross sections of potential temperature (contour interval $1 \mathrm{~K}$ ) and cross-section-parallel wind component (arrows and shading, shading increment $5 \mathrm{~m} \mathrm{~s}^{-1}$ ) along the line indicated in Fig. 3a. Model results are valid at 06 UTC for simulations (a) W, (b) E.

related to the large-scale lifting of the flow approaching the Alps.

Finally, southerly ambient flow is also associated with fairly weak low-level wind speeds in the northern Alpine foreland. This is related to the fact that southerly flow (unless in exceptionally strong cases) tends to be associated with a hydraulic jump over the Alpine foothills (not shown). Therefore, the nocturnal surface temperature minima are comparatively low in the S case, although the broad-scale subsidence in the lee of the Alps leads to the highest daytime maxima.

\section{CONCLUSIONS}

The most interesting result found in this study is that the effects of upstream lifting and lee-side subsidence dominate the Alpine impact on the low-level temperature field in the northern foreland only during the day. At night, low-level temperatures generally tend to be lower for easterly wind directions than for westerly ones, which can be mainly traced back to differences in the turbulent vertical mixing. The mixing is strongest for northwesterly flow because a low-level jet forms along the Alpine foothills, followed by westerly flow due to the asymmetric flow deflection around the Alps. Another important factor contributing to the difference between easterly and westerly flow is the friction-induced ageostrophic wind component, which is directed towards the Alps for easterly flow and away from the Alps for westerly flow.

\section{REFERENCES}

Grell, G. A., J. Dudhia, and D. R. Stauffer, 1995: A description of the fifth-generation Penn State/NCAR mesoscale model (MM5). NCAR Tech. Note NCAR/TN-398+STR, 122 pp.

Zängl, G., 2005: Large-scale-flow interactions with the Alps and their impact on the low-level temperature field in the northern foreland. Met. Z., in press. 